\title{
MODELO DE INTEGRAÇÃO EM SALA DE AULA: DROGAS COMO MOTE DA INTERDISCIPLINARIDADE
}

\author{
Models of integration in classroom: \\ drugs as an issue of the interdisciplinary
}

Marilde Beatriz Zorzi Sá ${ }^{1}$ • Jaime da Costa Cedran ${ }^{2}$. Débora Piai ${ }^{3}$

Resumo: O presente trabalho apresenta a descrição e resultados de uma atividade trabalhada com alunos do Ensino Médio e cujo tema abordado foram "as drogas". A ideia era que, utilizando um tema de grande repercussão e interesse dos jovens, amplamente discutido e de vasta relevância social, poderse-ia trabalhar de maneira interdisciplinar e de forma contextualizada, contribuindo para a construção de conhecimentos relacionados ao ensino de Ciências. Nessa perspectiva, foi proposta uma sequência de atividades interdisciplinares, como pesquisas, produção de painéis e elaboração de reportagem, dentro do referido tema, que revelaram a importância da integração dos saberes e a reflexão sobre o assunto trabalhado. Os resultados obtidos mostraram que o interesse e o envolvimento dos alunos foram grandes, o que possibilitou a aquisição de aprendizagens realmente significativas.

Palavras-chave: Ensino Médio. Drogas. Interdisciplinaridade. Ensino de ciências.

\begin{abstract}
This paper presents a description and results of an activity with high school students, whose topic was "Drugs". The idea was that, using a theme of great impact and interest to young people, which is widely discussed and of social relevance, the theme could be included in an interdisciplinary and contextualized way contributing to the construction of knowledge related to the Science teaching. Through this perspective, a series of interdisciplinary activities such as research, development and production of posters, within that theme was suggested, which revealed the importance of integration of knowledge and reflection on the subject worked on. The results showed that the interest and involvement of the students was great, which allowed the acquisition of learning to be really significant.
\end{abstract}

Keywords: High school. Drugs. Interdisciplinarity. Science teaching.

${ }^{1-3}$ Departamento de Química, Universidade Estadual de Maringá (UEM). Avenida Colombo, 5790, Campus

Universitário. Maringá, PR, Brasil.87.020-900. mari.zorzi@hotmail.com 
Sá, M. B. Z.; Cedran, J. C.; Piai, D.

\section{A abordagem interdisciplinar de um tema social}

Muito se fala e se discute sobre a necessidade da passagem de uma educação com foco na forma disciplinar para uma educação com o foco na interdisciplinaridade, mas, ainda são poucos aqueles professores que, mesmo acreditando em tal necessidade, ousam sair de seu estado de aparente conforto para se arriscarem em atividades e aulas que atendam a tais expectativas, pois a mudança de postura, a ruptura com concepções e práticas antigas de educação exige um grande envolvimento, criatividade, empenho, dedicação e, principalmente, tempo, o que acaba se transformando em grandes motivos para a falta de mudança. Para que contemplemos a interdisciplinaridade em nossas escolas e em nossas aulas, precisamos pensar em um ensino que esteja em sintonia com questões sociais, políticas, econômicas e éticas, o que não pode ser resolvido por uma única área do conhecimento ou disciplina que trabalhe isolada, e sim por várias áreas que possuam um objeto de estudo em comum. Assim, é importante que se tenha clareza da necessidade de mudanças de atitudes frente aos desafios do processo de ensino e de aprendizagem, como, também, a articulação entre as diferentes áreas do conhecimento.

Não se cogita em descentralizar as disciplinas, confundindo-as todas em práticas comuns ou indistintas; o que interessa é promover uma ação concentrada do seu conjunto e também de cada uma delas a serviço do desenvolvimento de competências gerais que dependem do conhecimento disciplinar. (BRASIL, 2002, p. 16)

Fazendo uma análise histórica, percebemos que, apesar de o conhecimento científico ser único, ele vem se fragmentando com o passar do tempo e com o acúmulo de conhecimento, aparecendo, assim, as diversas ciências que conhecemos hoje. Tornou-se, assim, quase impossível a um indivíduo conhecer a fundo todas as áreas. Com a fragmentação do conhecimento, a forma como ele vem sendo abordado também se fragmentou, e, consequentemente, gerou a educação compartimentalizada que temos hoje.

Essa visão fragmentada é repassada, inclusive, nos cursos de formação de professores, que, por sua vez, terão a mesma prática sedimentada em sala de aula, formando um ciclo de visões compartimentalizadas em todos os níveis, o que torna intrincada a percepção real do que é a Ciência, em qualquer grau de escolaridade, dificultando, assim, a noção da sua utilidade.

Em se tratando de ensino, por exemplo, sabemos que os currículos das disciplinas tradicionais, da forma como vêm sendo desenvolvidos, oferecem ao aluno apenas um acumulo de informações pouco ou nada relevantes para a sua vida profissional, principalmente porque o desenvolvimento tecnológico atual é de tal diversidade que se torna impossível processar, com a velocidade adequada, a esperada sistematização que a escola requer. (FAZENDA, 2002, p. 15)

Acreditamos que uma forma de mudar a visão simplificadora da ciência é mediar o processo de aprendizagem, possibilitando a compreensão da mesma pelo educando. Com esse 
Modelo de integração em sala de aula: ...

espectro geral, é possível que as pessoas identifiquem em seu dia a dia o contexto da Ciência e tenham a capacidade de verificar a integração das várias áreas do conhecimento na resolução de problemas cotidianos.

Segundo Ivani Fazenda (2002), a preocupação em integrar diversas áreas do conhecimento no ensino apareceu em meados da década de 1960, e somente no início da década de 1990 a interdisciplinaridade passa a ser tema-chave dos mais representativos eventos de educação. Apesar de parecer uma nova forma de pensar a Ciência, essa visão unificada já era acometida, desde os filósofos, com seus olhares atentos à natureza, ou seja, "são formas modernas de resgate de velha sabedoria" (PHILIPPI et al., 2000, p. 80).

Assim, são grandes os esforços na área de educação para que o olhar integrado e geral da Ciência permeie as aulas e a prática social. Entre os diversos níveis de integração, tem-se a interdisciplinaridade, que é uma das formas mais procuradas como instrumento de unificação de conhecimentos nas instituições de educação. Essa possui vários níveis de integração, que vão desde: interdisciplinaridade heterogênea, que é dedicado à combinação de programas com visão geral de conhecimentos e sem aprofundamento, até a interdisciplinaridade unificadora, resultante da integração metodológica e teórica de diferentes disciplinas (FAZENDA, 1979). A interdisciplinaridade só vale a pena se for uma maneira eficaz de se atingir metas educacionais previamente estabelecidas e compartilhadas pelos membros de uma unidade escolar, e quando pressupõe uma articulação voluntária e coordenada das ações disciplinares orientadas por um interesse comum (CARLOS, 2007). Ela deve promover uma educação científica mais abrangente e que envolva práticas integradas ao processo de ensino e aprendizagem significativas, e que permitam o estabelecimento de inter-relações entre os conhecimentos disciplinares e destes com o cotidiano, de uma forma fundamentada e planejada (BATISTA; SALVI, 2006).

Além disso, como citado por Hartmann e Zimmermann (2007, p. 3):

Considerando a velocidade e a quantidade de informações que chegam ao cidadão comum, a interdisciplinaridade é um princípio pedagógico importante para a formação dos estudantes. Ela os capacita a construir um conhecimento integrado e a interagir com os demais levando em conta que, em função da complexidade da sociedade atual, as ações humanas repercutem umas em relação às outras.

Como relatado anteriormente, é crescente a preocupação em unificar os saberes científicos. Assim, a articulação interdisciplinar que se espera deve ser promovida por um aprendizado com contexto para que não se torne uma aprendizagem fragmentada e ineficaz para o aluno. Dessa forma, o presente trabalho teve como finalidade integrar diferentes áreas do conhecimento, abordando um tema amplamente discutido em toda a sociedade: as drogas.

O uso de entorpecentes é um assunto de amplo interesse entre os adolescentes, um grande problema social e tema bastante divulgado nos diversos meios de comunicação, portanto, a escola não pode se eximir de trabalhar com tal assunto, uma vez que o que se deve ter em mente é a educação integral do aluno (MARTINS; MARIA, AGUIAR, 2003). Devido a essa relevância, propôs-se um trabalho de forma a unir diversas áreas do conhecimento e com a intenção de permitir que os educandos formem opiniões fundamentadas e críticas sobre o assunto. 
Sá, M. B. Z.; Cedran, J. C.; Piai, D.

\section{Metodologia e universo da pesquisa}

O trabalho se desenvolveu em um Colégio da Cidade de Maringá, estado do Paraná, e tinha como objetivo trabalhar com um tema que envolvesse os alunos por ser de interesse dos mesmos e por ter relevância social. A forma de trabalho deveria envolver várias áreas do conhecimento, ser interdisciplinar e contextualizada, para que pudesse contribuir para a construção de conhecimentos relacionados ao ensino de ciências por parte dos alunos. O tema escolhido foi "As Drogas" e, durante a atividade, os alunos deveriam perceber como as drogas contribuem para a afinação ou não da sociedade, já que essa escola trabalha com oficinas de aprendizagem, e esta oficina tinha como tema "Um mundo em constante afinação".

Todas as oficinas desenvolvidas na escola possuem um desafio que deve ser respondido pelos alunos. O desafio dessa oficina consistia na seguinte frase: um instrumento musical afinado é aquele que está pronto para uso. Ao considerar o nosso planeta como um grande instrumento, com inúmeros acordes, tons e melodias, como "anda" esta afinação? De acordo com essa temática, os professores decidiram trabalhar o tema "drogas".

A atividade teve início no primeiro dia de aula do terceiro bimestre (início de agosto), quando os alunos receberam orientações para o desenvolvimento da mesma. A primeira etapa a ser desenvolvida constava de coleta e seleção de materiais para a realização de uma pesquisa em equipe. Cada grupo de alunos escolheu um tipo droga para ser trabalhada. Nessa pesquisa foram investigados fatos históricos relacionados às drogas, formas de obtenção, funções orgânicas, efeitos biológicos (imediatos e de longo prazo), utilizações e custos sociais que as mesmas impõem. Os resultados da pesquisa deveriam ser apresentados aos professores no final do mês de agosto.

Em seguida, as equipes deveriam procurar fotos que retratassem o uso de drogas, e elas deveriam ter caráter formativo, portanto, não poderiam fazer apologia ao uso de drogas. As fotos foram entregues até meio do mês de setembro.

Ao final do mês de setembro, as equipes montaram painéis e apresentaram para os demais colegas da escola, como forma de socialização, aquisição, construção e ampliação de conhecimentos. Neles foram colocadas fotos, e as principais informações pesquisadas de maneira a informar e conscientizar a todos a respeito do tema. Os painéis foram distribuídos pela escola para continuassem a chamar a atenção dos alunos.

$\mathrm{Na}$ semana seguinte à apresentação dos painéis, cada equipe produziu um texto em que foram abordadas informações contidas na pesquisa teórica. O texto deveria apresentar características de uma reportagem de jornal ou revista, ser digitado e ilustrado. $\mathrm{O}$ foco de tal texto eram os custos sociais da utilização das drogas e a resposta ao desafio da oficina. Esse texto foi realizado juntamente com a professora de Produção Textual. Além das pesquisas que foram feitas anteriormente, os alunos foram incentivados a buscar outros dados para a realização desse texto. Dessa forma, realizaram enquetes dentro e fora da escola, bem como entrevistas com diversas pessoas que pudessem trazer relatos importantes para a produção textual.

Posteriormente, os dados estatísticos foram tratados com o auxílio do professor de Matemática; nesta fase da atividade, os alunos construíram gráficos e tabelas que traduziam os resultados obtidos.

Como última sequência de trabalho, os professores escolheram o melhor artigo. Esse foi revisado e publicado, em nível escolar, para que o conhecimento fosse socializado. 
Modelo de integração em sala de aula: ...

Ao final do trabalho, os alunos fizeram um relato como forma de avaliação da atividade. Nele, foram mencionadas as superações positivas ou negativas de suas expectativas, a relevância do trabalho e importância de uma atividade integrando várias áreas do conhecimento como metodologia de ensino.

Também foi realizada uma avaliação por parte dos professores que participaram da atividade. A intenção foi rever posturas, estratégias, refletir sobre mudanças para aumento de qualidade, estudar maneiras para que os conhecimentos construídos durante a execução da atividade pudessem ser ainda mais socializados, além de adequar a atividades para outras oficinas.

Posteriormente, foram selecionados trechos em que os educandos posicionavam-se em relação ao trabalho. Após a pesquisa, todos os conceitos foram abordados e discutidos em sala, auxiliados pelos professores das áreas de Educação Física, Química e Biologia.

\section{Reflexões sobre os resultados}

Como os relatos consideram os enfoques de superação das expectativas, relevância do trabalho e intermédio integrado dos professores, as discussões serão feitas permeando-se esses aspectos, já que essa foi a forma de avaliação para a prática pedagógica/metodológica.

\section{(a) Superação de expectativas em relação ao trabalho}

A concepção de utilidade define-se naquilo que pode ser usado em algum momento. Segundo CHASSOT (1995, p. 75), esse conceito define-se em "tudo que satisfaça uma necessidade, ou um desejo". Nesse caso, o tema referido contempla a utilidade, já que se enquadra em um ponto social.

No trecho a seguir, fica explícita a importância do tema "drogas", e sua utilidade no ensino, o que consequentemente favorece a aprendizagem significativa, portanto a superação de expectativas:

Aluna A: "No trabalho desenvolvido sobre drogas, foram necessárias
pesquisas, as quais me surpreenderam ainda mais, pois desconhecia
todos os efeitos e reações que a cocaína provoca no corpo humano".

Além da relevância do tema, cabe ressaltar o envolvimento dos alunos como agentes integradores da pesquisa, aspecto positivo ressaltado pela Aluna B, sobretudo no que diz respeito à ação promovida na escola:

Aluna B: "Tivemos também que apresentar um texto jornalístico sobre o tema e o mais interessante foi a pesquisa que elaboramos no colégio com os alunos e vimos um resultado positivo que muitos não gostaram ou não tem intenção de experimentar o cigarro, após isso, fizemos além do texto jornalístico, um mini-jornal com todas as informações pesquisadas". 
Sá, M. B. Z.; Cedran, J. C.; Piai, D.

Apesar das expectativas gerais terem sido alcançadas, no relato abaixo apresentado pela Aluna $G$, pode-se constatar que nem todos os alunos supriram suas expectativas, e nesse caso, o fechamento do trabalho poderia ter maior aprofundamento, especialmente no quesito social:

\begin{abstract}
Aluna G: "Um trabalho maior, com mais curiosidades poderia ser feito, com ajuda de todos, por ser um assunto cotidiano todos poderiam ajudar, não só com pesquisas do google, mas o que eles vêem nos jornais, suas opiniões, expressar aquilo que eles acham, os professores também, expor o que deveria ser feito para diminuir o uso dessas drogas".
\end{abstract}

Ainda no quesito expectativa, cabe ressaltar a importância do trabalho conjunto efetivo, e do papel do aluno como questionador/pesquisador da ação. Nem sempre esses aspectos são revelados e, em alguns casos, fica clara a ação para o aluno, mas a concretização tornase um empecilho na realização da atividade, sobretudo quando o trabalho é feito em grupo:

Aluna G: "Em resumo: procurar saber mais sobre o trabalho feito, pesquisar não só aquilo que se pede, mas ir além e claro pedir ajuda de professores e pessoas que entendam do assunto, uma ajuda de todos".

Dessa forma, fica claro quão efetivo é o trabalho quando o aluno é a peça principal da engrenagem, já que isso foi constatado nos excertos anteriores. Além da superação, em maioria positiva, sabemos que essa configuração permite formar educandos conscientes de seu trabalho e papel dentro da escola e sociedade.

\title{
(b) Relevância do tema
}

Ao tema "drogas" sempre foram conferidas várias expectativas da escola como um todo. É claro que, no universo dos alunos, esse assunto restringe-se, em muitos casos, ao uso dessas substâncias. No entanto esse tema, quando cogitado, deve ter caráter formativo, objetivando esclarecimento, como assinalado nos trechos abaixo:

Aluna B: "Ao final vimos os malefícios da droga, e a positividade em não querer fumar na maioria dos alunos do colégio, vendo que existem muitos alunos conscientes sobre o assunto".

Aluna C: "No trabalho abordamos sobre o álcool, uma droga que todos acham que não é uma droga, pois é sim. Nas pesquisas feitas podemos descobrir isso e muito mais, além de causar muitas doenças e muitas consequências para a vida do alcoólatra e para a família dele".

Aluno F: "Acredito que após ter feito o trabalho muitas dúvidas foram esclarecidas, até quem pensava em experimentar ou usava pensou em desistir devido aos perigos". 
Modelo de integração em sala de aula: ...

\section{(c) Interdisciplinaridade}

Embora o termo interdisciplinaridade não tenha sido mencionado nos relatos produzidos pelos alunos, fica clara a presença da integração entre os saberes, o que dá suporte para que o educando compreenda o assunto mencionado sob várias óticas:

Aluna A: "A formação do trabalho não envolveu somente o conhecimento químico, pois foram necessárias pesquisas históricas com informação em datas e anos, biológicas para relatar as reações que o corpo se encontra após o consumo, entre outras".

Aluna C: "O nosso trabalho foi abordado várias matérias; a sociologia foi uma delas, pois o álcool envolve toda a sociedade e temos também a questão da saúde que envolve a biologia, assim como a química com suas fórmulas".

Aluno D: "Foi um trabalho diferente, pois envolvia várias matérias como química, português, matemática e biologia. A química envolviase, pois o ecstasy é uma droga química, feita em laboratório. Em português pelo texto jornalístico que fizemos com base nas reportagens que pesquisamos. Se relaciona com a matemática pelas estatísticas e gráficos que pesquisamos, também na biologia pelos efeitos que as drogas fazem no corpo humano".

O trabalho interdisciplinar possui vários aspectos fortalecedores da aprendizagem. No entanto requer exímio trabalho dos alunos, como pesquisa, discussão, reflexão, bem como outras habilidades. Nesse caso, alguns alunos encontram dificuldades em desdobrar essas habilidades no fortalecimento de competências, como, por exemplo, conseguir descentralizar conceitos específicos, chegando a uma visão geral do tema:

Aluno E: "A interdisciplinaridade que abrange qualquer trabalho foi
uma das grandes dificuldades, a cocaína, por exemplo, envolve muita
coisa, na química, por exemplo, estudamos sua fórmula, composição
molecular. Na biologia estudamos os efeitos causados pela droga, em
sociologia e psicologia estudamos como a cocaína e o usuário implica-
ria na sociedade e estudamos a historia da droga etc".

Como dito, apesar desses trabalhos possuírem caráter positivo em sua maioria, nem todos os educandos atingem as expectativas do trabalho. Como relatado pela Aluna H, essas atividades necessitam de grande comprometimento por parte de todos, já que, na interdisciplinaridade, os conceitos possuem um "norte" que permeia os conteúdos, além da integração, que, por muitas vezes, gera atividades de grandes proporções: 
Sá, M. B. Z.; Cedran, J. C.; Piai, D.

Aluna H: "Outro fator que vale a pena ser citado, é a metodologia versus comprometimento do aluno propriamente dito. Talvez, a maturidade não seja suficiente junto a seriedade para trabalhos dessa escala gerando frustrações por parte do professor e do aluno".

Outro problema enfrentado na interdisciplinaridade é o grande tempo necessário para a realização de atividades e o desenvolvimento de conceitos de forma aprofundada pelas disciplinas. Alguns estudiosos nessa área chegam a se questionar sobre a validade desse método de trabalho, já que é impossível ter conhecimento profundo sobre todas as coisas (FAZENDA, 1979). No trecho abaixo, fica clara que nem sempre esse tipo de metodologia supre a necessidade de alguns alunos, especialmente os que possuem a visão tradicional que a sociedade e, em particular, algumas universidades possuem:

\begin{abstract}
Aluna H: "No fim, o trabalho ficou dentro das expectativas, mas nem todos da equipe aproveitaram, além de ocuparem tempo de outras atividades individuais voltadas ao vestibular, mesmo sendo um tema de conhecimentos gerais".
\end{abstract}

\title{
Considerações finais
}

Todas as alternativas para tornar significativa a aprendizagem são efetivas dentro de sala de aula, cada qual com sua especificidade, e isso fica claro à medida que os alunos relatam suas experiências de trabalho. Dessa forma, vale ressaltar que a interdisciplinaridade é um bom caminho a ser seguido, e que, como todas as outras metodologias, possui aspectos relevantes e outros que não se enquadram a determinadas situações.

O ideal de trabalho, nesse sentido, vai além de uma metodologia isolada aplicada na escola; é necessária a integração das instituições de ensino formadoras de educadores, que, por muitas vezes, possuem seus programas restritos e sedimentados. Integração, também, das instituições com o governo, já que nem sempre estas possuem autonomia para algumas mudanças necessárias, como o tempo para a preparação, adaptação e capacitação para metodologias alternativas que tornam o ensino utilitário, bem como a grade de conteúdos relevantes à aprendizagem para a vida.

Assim, integrar os conhecimentos mostrou-se positivo, já que, dessa forma, os alunos demonstraram visão amplificada sobre o tema drogas, quebrando o paradigma tradicional da educação centralizadora e fragmentada. 
Modelo de integração em sala de aula: ...

\section{Referências}

BATISTA I. L.; SALVI, R. F. Perspectiva pós-moderna e interdisciplinaridade educativa: pensamento complexo e reconciliação integrativa. Ensaio: Pesquisa em Educação em Ciências, Belo Horizonte, v. 8, n. 2, p. 147-160, 2006.

BRASIL. Ministério da Educação. PCN ensino médio: orientações educacionais complementares aos parâmetros curriculares nacionais - ciências da natureza, matemática e suas tecnologias. Brasília: Secretaria da Educação Média e Tecnológica, 2002. Disponível em: $<$ http://portal.mec.gov.br/index.phd?option $=$ com_content\&view $=$ article\&cid $=12598$ : puplicacoes $>$. Acesso em: 14 abr. 2010.

CARLOS, J. G. Interdisciplinaridade no ensino médio: desafios e potencialidades. 2007. 171 f. Dissertação (Mestrado em Ensino de Ciências) - Instituto de Física, Universidade de Brasília, Brasília, 2007. Disponível em: <http://bdtd.bce.unb.br/tedesimplificado/ tde_busca/arquivo.php?codArquivo=2172>. Acesso em: 04 maio 2010.

CHASSOT, A. Para quem é útil o ensino?: alternativas para um ensino (de química) mais crítico. Canoas: Editora da ULBRA, 1995.

FAZENDA, I. C. A. Integração e interdisciplinaridade no ensino brasileiro: efetividade ou ideologia? São Paulo: Loyola, 1979.

Interdisciplinaridade: um projeto em parceria. São Paulo: Loyola, 2002.

HARTMANN, A. M.; ZIMMERMANN, E. O trabalho interdisciplinar no ensino médio: a reaproximação das "duas culturas". Revista Brasileira de Pesquisa em Educação em Ciências, São Paulo, v. 7, n.2, p. 1-16, 2007.

MARTINS, A. B.; MARIA, L. C.; AGUIAR, M. M. P. As drogas no ensino de química. Química Nova na Escola, São Paulo, n. 18, p. 18-21, 2003.

PHILIPPI, A. et al. Interdisciplinaridade em ciências ambientais. São Paulo: Signus, 2000.

Artigo recebido em 15/09/2011. Aceito em 12/04/2012. 
